\title{
INFLUÊNCIA DOS TRATAMENTOS TERMOMECÂNICOS NA ABSORÇÃO DE HIDROGÊNIO NO ZIRCÔNIO PURO*
}

Rodrigo Vitorino da Silva ${ }^{1}$ Rafaella Martins Ribeiro ${ }^{2}$ Dilson Silva dos Santos ${ }^{3}$

\section{Resumo}

Ligas a base de zircônio são utilizadas na indústria nuclear devido à suas boas propriedades mecânicas, baixa absorção de nêutrons e boa resistência à corrosão. No entanto, durante a operação do reator, o hidrogênio é absorvido pela liga, resultando na formação de hidretos. Para aumentar o tempo de operação desses componentes é necessário o desenvolvimento de novas ligas que retardem ou diminuam esse efeito. Este trabalho tem como objetivo avaliar a influência dos tratamentos termomecânicos no zircônio puro, através de testes que avaliem a corrosão, absorção e dessorção de hidrogênio nas condições laminada a frio e tratada termicamente. Análises de difração de raios- $X$ indicam a existência de uma matriz Zr- $\alpha$ para as condições analisadas. Após a hidrogenação são formados $\mathrm{ZrH}$ e $\mathrm{ZrH}_{2}$. O zircônio puro encruado absorveu $1,23 \% \mathrm{p} \mathrm{H}$. O zircônio puro laminado e tratado termicamente absorveu $0,85 \% \mathrm{p} \mathrm{H}$. O resultado de DSC mostra que a decomposição dos hidretos ocorre em faixas de temperatura entre 318 e $368^{\circ} \mathrm{C}$ para a condição tratada termicamente. Para condição laminada, o resultado mostra uma transformação de fase entre 565 e $650^{\circ} \mathrm{C}$. O conjunto de resultados permite concluir que a amostra tratada termicamente absorve menos hidrogênio, porém o início do processo é menor. A amostra tratada termicamente é menos resistente a corrosão e a velocidade da corrosão é menor.

Palavras-chave: Zircônio; Hidrogênio; Laminado; Tratado termicamente.

\section{THE INFLUENCE OF THERMOMECHANICAL TREATMENTS IN THE CAPTURE OF HYDROGEN IN ZIRCONIUM PURE}

\section{Abstract}

Zirconium based alloys are used in nuclear industry owing to its good mechanical properties, neutrons's low capture and good corrosion resistance. However, during operation of the reactor, the hydrogen is absorbed by the alloy, resulting in the formation of hydrides. To increase the operating time of these components is necessary to develop new alloys that delay or reduce this effect. The aim of the work is evaluate the influence of the thermomechanical treatment in zirconium pure through corrosion, hydrogen absorption and desorption tests in cold-rolled and annealed condition. XRD analysis indicates the existence of a $\mathrm{Zr}-\alpha$ for all the conditions analyzed. After the hydrogenation, were formed $\mathrm{ZrH}$ e $\mathrm{ZrH}_{2}$. The zirconium pure cold-rolled absorbed $1,23 \% \mathrm{wt} \mathrm{H}$. The zirconium pure cold-rolled and annealed condition absorbed $0,85 \% \mathrm{wt} \mathrm{H}$. The DSC results show that the hydride decomposition occurs at temperature ranges between 318 and $368^{\circ} \mathrm{C}$ for the annealed condition. For cold-rolled condition, the result shows a phase transformation between 565 and $650^{\circ} \mathrm{C}$. The results indicate that the sample annealed condition absorbs less hydrogen, but the beginning of procedure is smaller. The sample annealed condition is less resistant corrosion and the velocity of corrosion is smaller.

Keywords: Zirconium; Hydrogen; Cold-rolled; Annealed treatment.

1 Graduando em Engenharia de Materiais do PEMM, COPPE, Universidade Federal do Rio de Janeiro (UFRJ), RJ, Brasil.

2 Doutora em Eng. Metalúrgica e Materiais e Professora do PEMM, COPPE, UFRJ, RJ, Brasil.

3 Físico, DSc em Eng. Metalúrgica e Materiais e Professor do PEMM, COPPE, UFRJ, RJ, Brasil. 


\section{INTRODUÇÃO}

O zircônio e suas ligas são utilizados para a fabricação das varetas combustíveis de reatores nucleares devido às suas propriedades de baixa absorção de nêutrons e alta resistência à corrosão em ambientes de alta temperatura e pressão [1].

Nas condições de operação dos reatores de água pressurizada PWR (Pressurized Water Reactor) a $320^{\circ} \mathrm{C}$ e 160 atm ocorre a reação do zircônio com a água resultando na formação de $\mathrm{ZrO}_{2}$ e $\mathrm{ZrH}_{2}$, reduzindo a ductilidade e a tenacidade à fratura. [2] A forma mais eficaz de reduzir ou retardar a absorção de hidrogênio e a consequente formação de hidreto é através do controle dos processos de fabricação das varetas. As ligas de zircônio comerciais mais importantes, como a $\mathrm{Zr}-1 \mathrm{Nb}$, são totalmente ou parcialmente recristalizadas e são constituídas de uma matriz $\mathrm{Zr}$ - $\alpha$, contendo $\mathrm{Nb}$ em solução sólida e precipitados finos de $\mathrm{Nb}-\beta$. Esta configuração permite a combinação de alta resistência à fluência $[3,4]$ e pequenas mudanças dimensionais causadas pela irradiação. [5]

Este trabalho tem como objetivo analisar a influência dos tratamentos termomecânicos na absorção de hidrogênio no zircônio puro. As condições de formação de hidreto em microestruturas oriundas de diferentes condições de processamento termomecânico serão analisadas através de ensaios de cinética de absorção, de calorimetria diferencial de varredura e de polarização. As fases existentes no zircônio puro antes e após a hidrogenação foram descobertas por difração de raios-X. Os resultados serão comparados com ligas de zircônio estudadas anteriormente.

\section{MATERIAIS E MÉTODOS}

\subsection{MATERIAIS}

\subsubsection{Fusão do zircônio}

Para o desenvolvimento deste trabalho foi realizada a fusão do zircônio puro, de qualidade nuclear, fornecida pelas Indústrias Nucleares do Brasil (INB). A fusão da carga foi realizada no forno elétrico a arco Bühler AM VARIO 400. A fusão foi realizada sob atmosfera de argônio e resultou num lingote de $60 \mathrm{~g} \mathrm{com} 9 \mathrm{~mm}$ de espessura e $100 \mathrm{~mm}$ de comprimento.

\subsection{PROCESSAMENTO TERMOMECÂNICO}

\subsubsection{Laminação a frio}

A laminação foi realizada à temperatura ambiente no laminador FENN 150 HARTFORD, CONN, HORSBURGH e SCOTT, onde obteve um grau de redução de $80 \%$ através de passes de $0,2 \mathrm{~mm}$. Nesta etapa foi obtida uma chapa com $1,8 \mathrm{~mm}$ de espessura.

\subsubsection{Tratamentos térmicos}

Foi realizado um tratamento térmico $700{ }^{\circ} \mathrm{C}$ por $4 \mathrm{~h}$ em um forno tubular Carbolite, com resfriamento ao ar. As amostras foram encapsuladas em tubos de quartzo sob vácuo para reduzir a oxidação superficial durante o tratamento térmico. 


\subsection{Cinética de Absorção de Hidrogênio}

As medidas de cinética de absorção de hidrogênio foram realizadas no equipamento PCT Pro 2000 HyEnergy, nas condições laminada a frio e tratada termicamente a $700{ }^{\circ} \mathrm{C}$ por $4 \mathrm{~h}$, numa temperatura de $320^{\circ} \mathrm{C}$ sob uma pressão de 10 bar de $\mathrm{H}_{2}$ para determinar o percentual em peso de hidrogênio absorvido e o tempo em que a absorção ocorre. Estas condições foram escolhidas para simular as condições de operação do reator nuclear.

\subsection{Calorimetria Diferencial de Varredura}

O ensaio de Calorimetria Diferencial de Varredura (DSC) permite determinar a energia necessária para a decomposição de hidretos. Neste trabalho foram obtidas as temperaturas de dissociação do hidrogênio para as amostras de zircônio puro hidrogenadas nos ensaios de cinética de absorção. O equipamento utilizado foi Setaram Sensys Evo DSC. Os ensaios foram realizados a uma taxa de aquecimento de $10{ }^{\circ} \mathrm{C} / \mathrm{min}$ desde a temperatura ambiente até $800^{\circ} \mathrm{C}$.

\subsection{Ensaio de Polarização Potenciodinâmica}

O ensaio de polarização potenciodinâmica foi realizado para avaliar a resistência à corrosão das amostras de zircônio puro laminadas a frio e tratada termicamente em temperatura ambiente. O equipamento utilizado foi o potenciostato da marca AUTOLAB modelo PGSTAT 100N. O eletrodo de calomelano saturado (ECS) foi utilizado como referência para medir o potencial do eletrodo de trabalho, que neste caso é a amostra, e o contra eletrodo de platina foi utilizado para promover a corrente entre o eletrodo de trabalho e o contra eletrodo. O ensaio foi realizado em solução aquosa de $0,1 \mathrm{M}$ de $\mathrm{LiOH}$, base adicionada ao líquido refrigerante nos reatores nucleares. Para a curva de polarização catódica foi aplicada uma varredura do potencial de circuito aberto, até um potencial de $-2 \mathrm{~V}$ e para a polarização anódica foi aplicada uma varredura do potencial de circuito aberto, até um potencial de $2 \mathrm{~V}$, utilizando uma variação de potencial de $0,3 \mathrm{mV}$ e uma taxa de medição de $600 \mathrm{mV} / \mathrm{s}$. Para a determinação da corrente de corrosão foi utilizado o método de Tafel. A partir da região da curva anódica e catódica considerada linear, foi traçada uma reta. O ponto onde essas duas retas se cruzavam foi considerado para o cálculo da corrente de corrosão.

\subsection{Difração de Raios-X}

A difração de raios-X (DRX) permitiu identificar as fases existentes em cada condição bem como a formação de hidretos nas amostras hidrogenadas. $O$ difratômetro utilizado foi o Shimadzu modelo XRD-6000 com monocromador de grafite e radiação de cobre $\mathrm{Cu}-\mathrm{Ka}$ cujo comprimento de onda é $\lambda=1,5457 \AA$. As identificações das fases foram feitas com a utilização do software Powdercell ${ }^{\circledR}$ e da base de dados do livro Pearson's Handbook Desk Edition [6]. Os testes de difração de raios- $X$ foram feitos com varredura contínua, no intervalo de $10^{\circ}$ a $90^{\circ}$, passo de $0,02^{\circ}$ e velocidade de $2 \% \mathrm{~min}$. 


\section{RESULTADOS E DISCUSSÃO}

\subsection{Ensaio de Polarização Potenciodinâmica}

As figuras 1 e 2 mostram as curvas de polarização catódica e anódica das amostras estudadas obtidas através do ensaio de polarização.

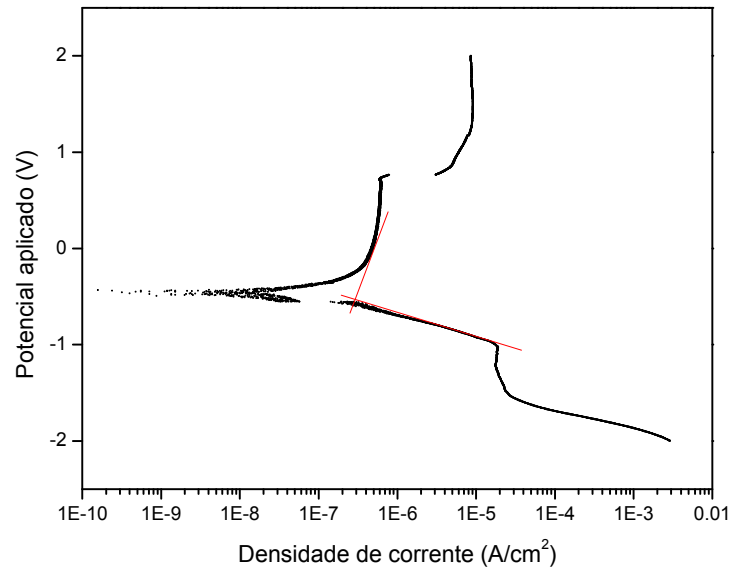

Figura 1. Curva de polarização do zircônio puro laminado a frio.

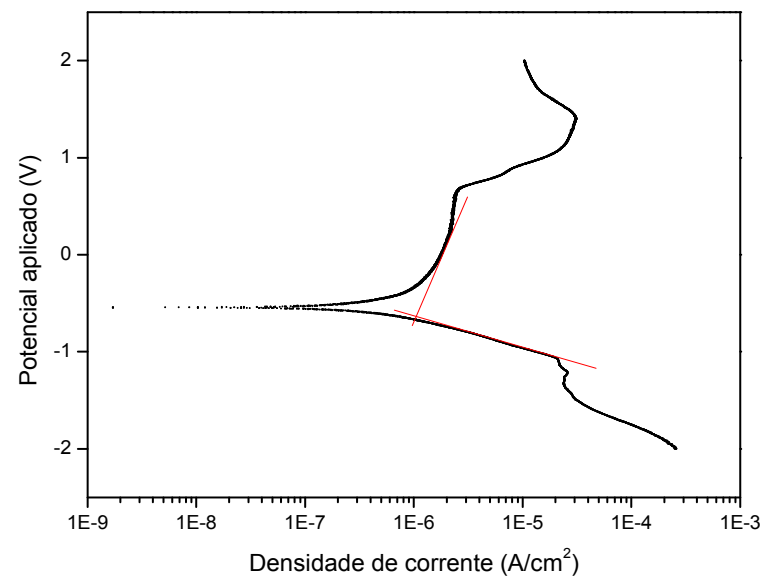

Figura 2. Curva de polarização do Zircônio puro, laminado e tratado termicamente a $750^{\circ} \mathrm{C}$ por 4 horas.

A curva de polarização para o zircônio puro na condição de laminada mostra que o ponto de encontro das duas retas se refere a um potencial aplicado de $-0,53 \mathrm{~V} \mathrm{e}$ densidade de corrente de $2,84 \times 10^{-7} \mathrm{~A} / \mathrm{cm}^{2}$. Como a área da amostra foi de 0,383 $\mathrm{cm}^{2}$, a corrente de corrosão encontrada para esta condição foi $1,09 \times 10^{-7} \mathrm{~A}$. Resultados similares foram obtidos por Ribeiro [7] ao estudar ligas a base de $\mathrm{Zr}-\mathrm{Nb}$ na mesma condição.

Para a amostra de zircônio puro laminada e tratada termicamente, o ponto de encontro das duas retas na curva de polarização se refere a um potencial aplicado de $-0,64 \mathrm{~V}$ e densidade de corrente de $1,04 \times 10^{-6} \mathrm{~A} / \mathrm{cm}^{2}$. Como a área da amostra foi de $0,177 \mathrm{~cm}^{2}$, a corrente de corrosão encontrada para esta condição foi $1,84 \times 10^{-7} \mathrm{~A}$.

\subsection{Calorimetria Diferencial de Varredura}

As análises de DSC permitiram determinar a faixa de temperatura onde ocorreu a dissociação dos hidretos formados nas amostras após a hidrogenação. A reação de 
dissolução dos hidretos é endotérmica, ou seja, a amostra absorve calor para que o hidreto se dissocie.

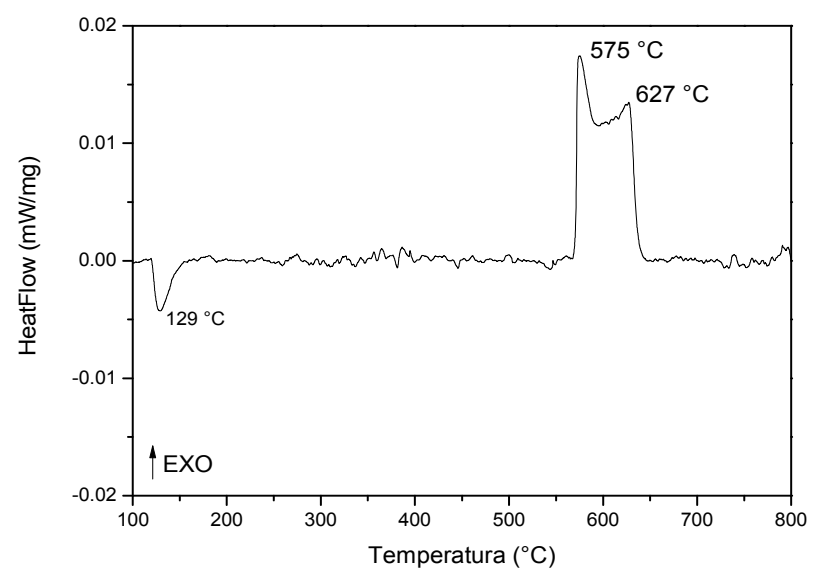

Figura 3. Curva de DSC do zircônio puro laminado.

A figura 3 mostra a curva obtida da análise de DSC para a amostra de zircônio puro laminado. A curva mostra que a dessorção ocorreu numa faixa de temperatura entre 119 e $155^{\circ} \mathrm{C}$, com um pico em $129{ }^{\circ} \mathrm{C}$. A curva apresenta também uma reação exotérmica numa faixa de temperatura entre 565 e $650{ }^{\circ} \mathrm{C}$, apresentando dois picos, um em $575^{\circ} \mathrm{C}$ e outro em $627^{\circ} \mathrm{C}$.

A reação exotérmica apresentada na curva indica uma transformação de fase da microestrutura, o que é comprovado através do diagrama $\mathrm{Zr}-\mathrm{H}$ [8]. Ao fixar a porcentagem em peso de $\mathrm{H}$ absorvido pela amostra na cinética de absorção $(1,23 \% \mathrm{p} \mathrm{H})$ no diagrama, é observado que ocorre uma transformação de $\mathrm{Zr}$ - $\alpha$ para $\mathrm{Zr}-\beta$, de estrutura cúbica, dentro da faixa de temperatura do pico exotérmico.

Para o pico endotérmico apresentado, não se pode afirmar se houve a dessorção de hidreto, uma vez que não foi encontrada nenhuma literatura que indique alguma dessorção a esta temperatura. Serão realizados mais ensaios e pesquisas para esclarecer o pico endotérmico encontrado.

A figura 4 mostra a curva obtida da análise de DSC para a amostra de zircônio puro laminado e tratado termicamente. Para esta condição, a dessorção ocorreu em faixas de temperatura entre 318 e $368{ }^{\circ} \mathrm{C}$, apresentando um pico em $320{ }^{\circ} \mathrm{C}$. Faixas de temperatura próximas foram encontradas por Ribeiro [7] ao analisar as ligas a base de $\mathrm{Zr}-\mathrm{Nb}$ em condições similares.

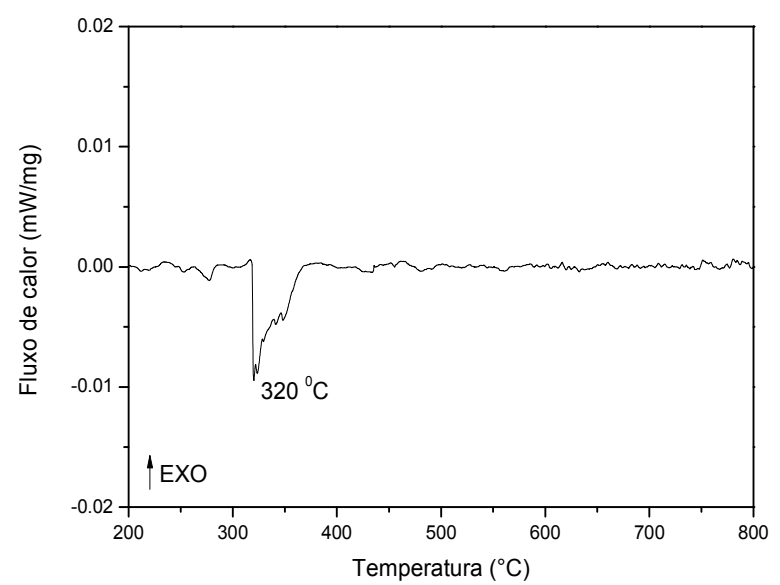

Figura 4. Curva de DSC do zircônio puro laminado e tratado termicamente a $700{ }^{\circ} \mathrm{C}$ por 4 horas. 


\subsection{Cinética de Absorção de Hidrogênio}

A figura 5 mostra as curvas obtidas dos testes de cinética de absorção de hidrogênio para o zircônio puro laminado e para o zircônio puro laminado e tratado termicamente.

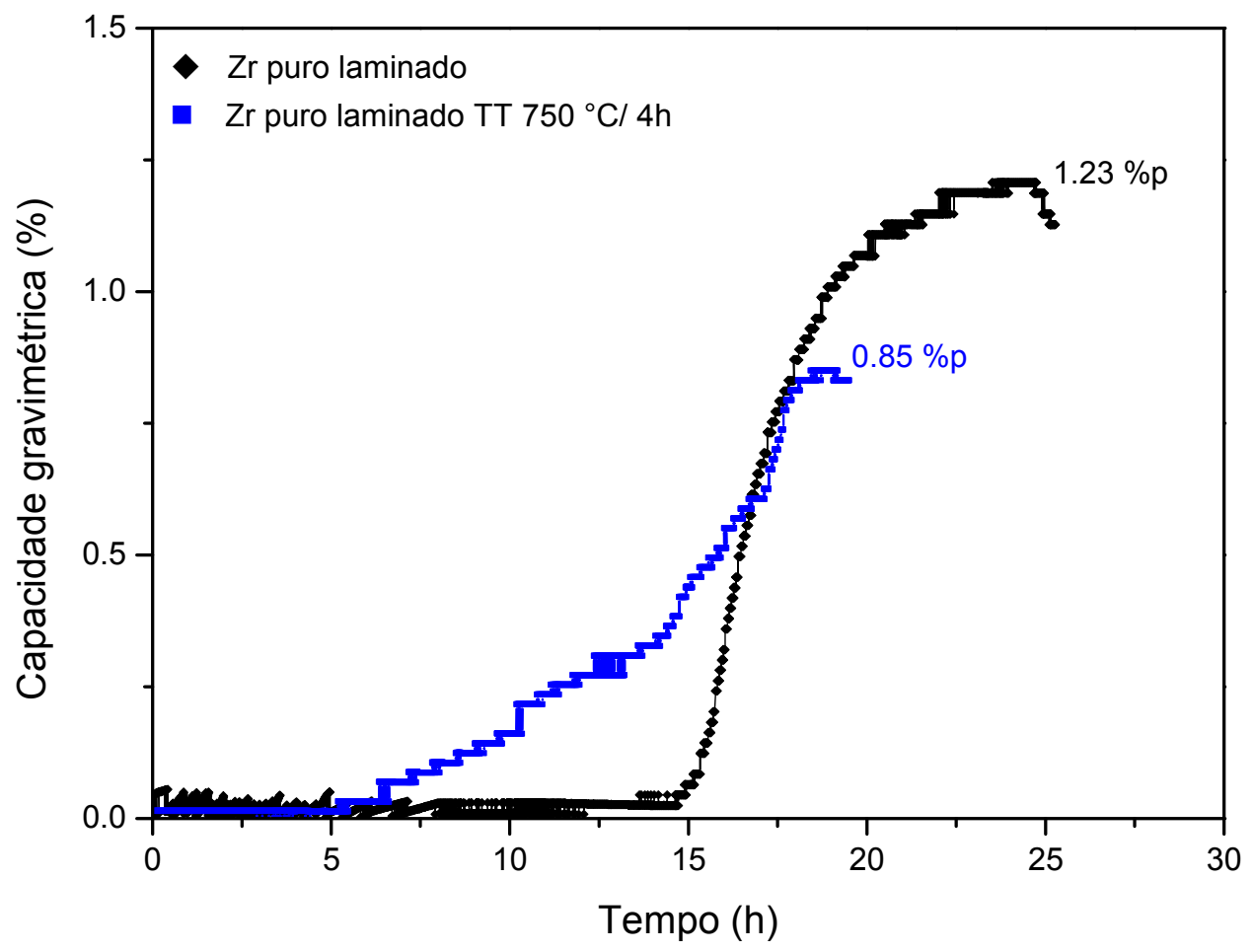

Figura 5. Curvas de cinética de absorção para as amostras estudadas numa temperatura de $320^{\circ} \mathrm{C}$ sob 10 bar de $\mathrm{H}_{2}$.

A amostra de zircônio puro laminado absorveu 1,23 \% $\mathrm{p}$ e o processo de absorção só iniciou após $15 \mathrm{~h}$. Em contrapartida, a amostra de zircônio puro laminado e tratada termicamente absorveu $0,85 \% \mathrm{p} \mathrm{H}$ e o processo de absorção se iniciou após $5 \mathrm{~h}$.

A interação do hidrogênio com a microestrutura depende da natureza dos defeitos existentes nas condições analisadas. $O$ fato da amostra laminada absorver mais hidrogênio é justificado pela forte energia de ligação do hidrogênio com as discordâncias e pela grande densidade de discordâncias presente na condição laminada (encruada). A redução da quantidade de hidrogênio absorvido para a amostra tratada termicamente se deve ao fato da ativação de mecanismos de recuperação (aniquilação de discordâncias) e recristalização, o que faz com que a densidade de discordâncias diminua com relação à condição anterior analisada.

\subsection{Difração de Raios-X}

Os difratogramas das amostras de zircônio puro nas condições laminada e tratada termicamente são apresentados a seguir nas figuras 6 e 7. 


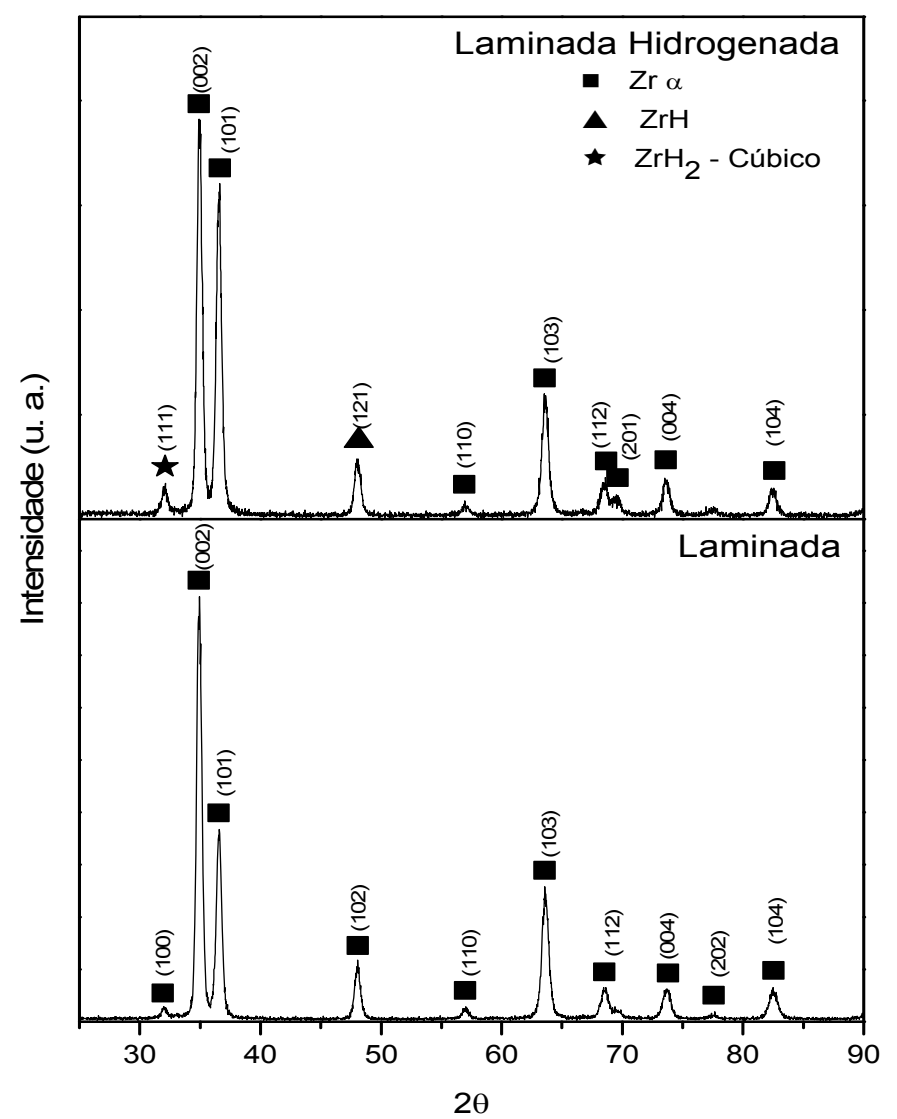

Figura 6. Difratograma do Zircônio puro laminado, antes e após a hidrogenação.

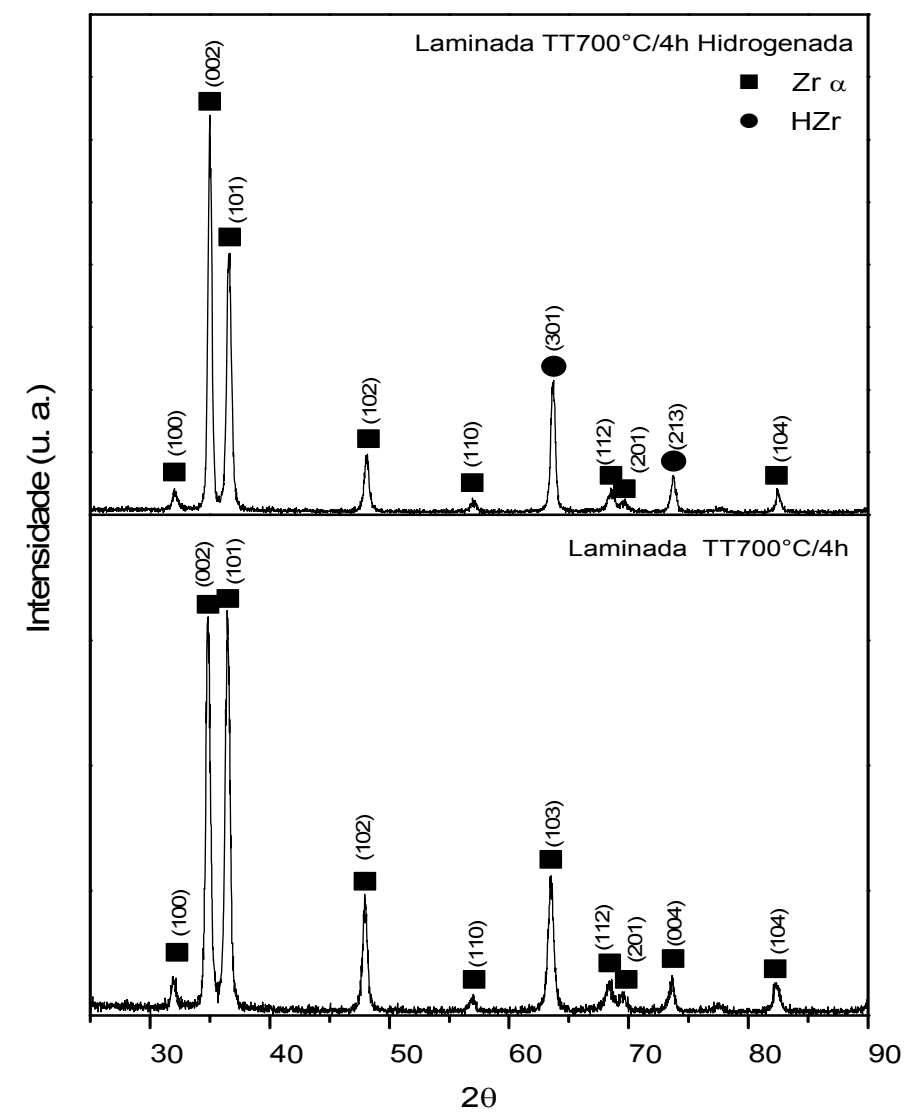

Figura 7. Difratograma do Zircônio puro laminado, tratado termicamente a $700^{\circ} \mathrm{C} / 4 \mathrm{~h}$, antes e após a hidrogenação. 
Os difratogramas das amostras sem hidrogênio indicam a presença da fase $\mathrm{Zr}$ - $\alpha$, de estrutura hexagonal compacta, para as duas condições analisadas. Em ligas a base de zircônio a matriz é composta pela fase $Z r-\alpha$, no entanto há a presença de precipitados finos, como os $\mathrm{Nb}-\beta$. [7]

Após a hidrogenação, o difratograma indica a formação de $\mathrm{ZrH}, \mathrm{ZrH}_{2}-\delta$ para a amostra laminada e a formação de $\mathrm{ZrH}$ para a amostra laminada e tratada termicamente. A formação de hidretos em condições similares de hidrogenação também foi observada por Gabriel [9] em uma liga $\mathrm{Zr}-1 \mathrm{Nb}$, em condições de hidrogenação similares à utilizada neste estudo.

\section{CONCLUSÂO}

As principais conclusões após os ensaios realizados sobre o efeito do tratamento termomecânico na absorção do hidrogênio no zircônio puro são apresentados abaixo.

As curvas de polarização mostram que o zircônio puro laminado é mais resistente a corrosão do que o zircônio puro laminado e tratado termicamente, embora a velocidade de corrosão para o zircônio puro laminado seja maior do que o zircônio puro laminado e tratado termicamente, já que a densidade de corrente de corrosão é maior.

A cinética de absorção de hidrogênio indica que o zircônio puro absorve maior quantidade de hidrogênio quando encruada, apesar de demorar mais tempo para absorver. O zircônio puro tratado termicamente absorve uma menor quantidade de hidrogênio, mas o processo se inicia mais rápido.

O resultado de DSC mostra que a decomposição dos hidretos ocorre numa faixa de temperatura entre 318 e $368{ }^{\circ} \mathrm{C}$ para o zircônio puro laminado e tratado termicamente e para o zircônio puro laminado houve uma transformação de fase numa faixa de temperatura entre 565 e $650{ }^{\circ} \mathrm{C}$.

\section{Agradecimentos}

Os autores agradecem ao CNPq, CAPES e FINEP pelo apoio financeiro a esta pesquisa.

\section{REFERÊNCIAS}

1 M.A. Vicente Alvarez, J.R. Santisteban, P. Vizcaino, A.V. Flores, A.D. Banchik, J.Almer, "Hydride reorientation in $\mathrm{Zr} 2.5 \mathrm{Nb}$ studied by synchrotron X-ray diffraction", Acta Materialia,2012, 60, 6892-6906

2 Martins, C. D., Síntese e caracterização de ligas a base de Zr-Nb para uso em reatores nucleares , Dissertação de M.Sc., Rio de Janeiro, RJ, Brasil, COPPE/UFRJ, 2013

3 V. Fidleris, "The effect of cold-work and stress-relieving on the irradiation growth behavior of zirconium alloys", J. Nucl., 1973, 46, 356-360

4 E.F. Ibrahim, "In-reactor tubular creep of Zircaloy-2 at 260 to $300{ }^{\circ} \mathrm{C}$ ", J. Nucl. Mater., 1973, 46, 169-182

5 Y.I. Jung, M.H. Lee, H.G. Kim, J.Y. Park, Y.H. Jeong, "Behavior of a recrystallization in HANA-4 and HANA-6 zirconium-based alloys", Journal of Alloys and Compounds, 2009, 479, 423-426.

$6 \quad$ P. Villars, Pearson's HandBook Desk Edition, Ohio, ASM International, 1997 
7 Ribeiro, R.M., Interação hidrogênio-microestrutura em ligas a base de Zr-Nb para aplicação em reatores nucleares, Tese de D.Sc., Rio de Janeiro, RJ, Brasil, COPPE/UFRJ, 2014.

8 Thermo-Calc Software, v.5.0.4.75, licença pertence ao Laboratório PROPMEC, base de dados TCBIN.

9 Gabriel, C. W., Estudo da precipitação de hidretos em ligas de zircônio para aplicações nucleares , Dissertação de M.Sc., COPPE/UFRJ, Universidade Federal do Rio de Janeiro, Rio de Janeiro, Brasil, 2011. 